\title{
A MODEL TO PREDICT THERMAL CONDUCTIVITY OF IRRADIATED U-Mo DISPERSION FUEL
}

\author{
Douglas E. Burkes ${ }^{\mathrm{a}}$, Tanja K. Huber ${ }^{\mathrm{b}}$, and Andrew M. Casella ${ }^{\mathrm{a}}$ \\ ${ }^{a}$ Pacific Northwest National Laboratory, Nuclear Engineering and Analysis Group \\ P.O. Box 999 MSIN K8-34, Richland, WA, USA 99352 \\ ${ }^{\mathrm{b}}$ Technische Universität München, Forschungs-Neutronenquelle Heinz Maier-Leibnitz \\ Lichtenbergstr. 1, D-85748, Garching, Germany
}

Corresponding Author Contact Information

Dr. Douglas E. Burkes

Nuclear Engineering \& Analysis Group

Pacific Northwest National Laboratory

P.O. Box 999, MSIN K8-34

Richland, WA, U. S. A. 99352

Phone 1 (509) 3724152

Fax 1 (509) 3752610

E-mail Douglas.Burkes@pnnl.gov

\section{Submitted to Journal of Nuclear Materials}

September 2015

Revised January 2016

This manuscript has not been published elsewhere and has not been submitted simultaneously for publication elsewhere. 


\begin{abstract}
Numerous global programs are focused on the continued development of existing and new research and test reactor fuels to achieve maximum attainable uranium loadings to support the conversion of a number of the world's remaining high-enriched uranium fueled reactors to lowenriched uranium fuel. Some of these programs are focused on assisting with the development and qualification of a fuel design that consists of a uranium-molybdenum (U-Mo) alloy dispersed in an aluminum matrix as one option for reactor conversion. Thermal conductivity is an important consideration in determining the operational temperature of the fuel and can be influenced by interaction layer formation between the dispersed phase and matrix and upon the concentration of the dispersed phase within the matrix. This paper extends the use of a simple model developed previously to study the influence of interaction layer formation as well as the size and volume fraction of fuel particles dispersed in the matrix, Si additions to the matrix, and Mo concentration in the fuel particles on the effective thermal conductivity of the U-Mo/Al composite during irradiation. The model has been compared to experimental measurements recently conducted on U-Mo/Al dispersion fuels at two different fission densities with acceptable agreement. Observations of the modeled results indicate that formation of an interaction layer and subsequent consumption of the matrix reveals a rather significant effect on effective thermal conductivity. The modeled interaction layer formation and subsequent consumption of the high thermal conductivity matrix was sensitive to the average dispersed fuel particle size, suggesting this parameter as one of the most effective in minimizing thermal conductivity degradation of the composite, while the influence of Si additions to the matrix in the model was highly dependent upon irradiation conditions.
\end{abstract}




\section{INTRODUCTION}

A significant number of the world's remaining high performance research reactors (HPRR) still utilize high-enriched uranium (HEU) to provide the high specific powers and neutron fluxes that make these reactors unique. Use of HEU can also result in extended residence time of the fuel in the core, higher specific reactivity, and, as a result, somewhat lower fuel cycle costs. With expanded interest in nuclear research, testing, energy, and medical isotopes; concerns over commerce of HEU and improved proliferation resistance of fuels and fuel cycles concomitantly increase. One of the main objectives of the Office of Material Management and Minimization Reactor Conversion Program (formerly referred to as the Reduced Enrichment for Research and Test Reactors Program and Global Threat Reduction Initiative) is to develop existing and new platetype and rod-type research and test reactor fuels to achieve maximum attainable uranium loadings. By increasing the uranium loading, enrichment reduction is possible to less than $20 \%$ (defined as low enriched uranium (LEU)) without significant penalties in safety, performance, or fuel cycle cost [1]. An enrichment level of less than 20\% has been recommended as the preferred enrichment level for research reactor fuels in order to minimize overall proliferation risks $[2,3]$.

Dispersion type fuels, commonly used in research and test reactors, consist of a fissile isotope bearing material that is uniformly distributed in a nonfissile material or diluent matrix. Dispersion fuel designs are unique and attractive for two primary reasons. First, fission-product damage can be localized, thereby minimizing damage to a structural matrix material. Second, use of a dispersion fuel design permits an increased choice of fuel systems and matrix materials that may otherwise normally be metallurgically incompatible [4]. The choice of a particular fuel system is guided and informed by dimensional stability under irradiation, thermal and physical properties, and compatibility of the dispersed phase with the matrix material at both fabrication and irradiation temperatures. The choice of matrix materials is principally guided and informed by physical and chemical properties. In large part, the properties of the matrix material will dominate the behavior of the fuel design itself, at least for lower volume loadings of fuel, such that the matrix should be ductile, insensitive to neutron damage, retain fission products, possess adequate corrosion resistance, have a comparable coefficient of thermal expansion to the cladding material, and possess high thermal conductivity. Efforts to develop and qualify a high density dispersion plate-type fuel are currently underway. Specifically, the fuel particles consist of a metastable gamma $(\gamma)$ phase uraniummolybdenum (U-Mo) alloy dispersed in an aluminum matrix that may be modified with silicon or other elements / compounds. The U-Mo alloy offers the ability to increase the uranium loading significantly, thereby allowing reduced enrichment and permitting the conversion of some of the worlds most powerful research and test reactors from HEU to LEU.

Thermal conductivity is an important consideration in determining the operational temperature of the fuel plate. In the case of dispersion fuels, thermal conductivity is primarily dependent upon the thermal conductivity of the matrix material itself, porosity that forms during fabrication of the fuel plates or rods, and upon the volume fraction of 
the dispersed phase. However, interactions between the dispersed phase and matrix as a result of interdiffusion can also play a role in thermal conductivity degradation that, in turn, could affect the operational temperature of the fuel. In the case of U-Mo dispersion fuels, the interaction layer (IL) that forms between the dispersed particles and the matrix reportedly consists of multiple compounds and may initially be formed during fabrication or irradiation and enhanced during irradiation [5]. The IL may possess a thermal conductivity that affects fuel performance [6], although direct measurements of the IL as a function of temperature and irradiation conditions have not been performed to the authors' knowledge. As a result, the thermal conductivity of the IL is often assigned a value lower than that of the dispersed fuel particle itself, with assumptions as low as 5.5 $\mathrm{W} \cdot \mathrm{m}^{-1} \cdot \mathrm{K}^{-1}$ [7] being used. Previously, the authors developed a simple model to predict the thermal conductivity of dispersion type fuel and investigated the sensitivity of this property to parameters such as volume fraction (loading), particle size, and IL thickness [8]. The model was compared to measurements performed on unirradiated U-Mo dispersion fuel samples. In the current work, thermal property measurements made on irradiated U-Mo dispersion fuel samples were used to calculate thermal conductivity. The simple model was extended to predict fuel meat thermal conductivity as a function of burnup / fission density based on sensitivities developed from the initial work in Reference 8 and compared to the irradiated U-Mo dispersion fuel thermal property measurements. Furthermore, the model takes advantage of recent thermal property information obtained on Al-Si matrices and irradiated U-Mo fuel.

\section{EXPERIMENTS}

The Advanced Test Reactor (ATR) Full-size Plate In Center Flux Trap Position (AFIP)-1 experiment was designed to demonstrate the performance of second-generation U-Mo dispersion fuel at a scale prototypic of research reactor fuel plates. The experiment was fabricated using commercially standard practices at Babcock \& Wilcox Nuclear Operations Group (B\&W NOG) in Lynchburg, VA. Atomized U-7wt\% Mo (nominal composition) fuel particles were supplied by the Korean Atomic Energy Research Institute (KAERI) using equipment intended for commercial supply. Two fuel plates were fabricated and irradiated as part of the experiment that incorporated two different matrix compositions: Al-2wt \% Si and Al-4043 ( 5wt\% Si). The fuel plates nominally contained 53.9 vol\% of $67 \mu \mathrm{m}$ average diameter fuel particles [9]. Fuel plates were subjected to a one hour pre-heat at $482{ }^{\circ} \mathrm{C}$ followed by hot rolling that subjected the fuel meat to $482^{\circ} \mathrm{C}$ for approximately another hour. The fuel meat was clad in aluminum alloy 6061 (AA6061) that contained typical Mg and Si impurities. The resultant fuel plates were nominally $57.2 \mathrm{~cm}$ long $\times 5.60 \mathrm{~cm}$ wide $\times 0.127 \mathrm{~cm}$ thick. The nominal fuel meat zone was $52.4 \mathrm{~cm}$ long $\times 3.68 \mathrm{~cm}$ wide $\times 0.0561 \mathrm{~cm}$ thick. The fuel plates were subjected to a blister anneal at $482{ }^{\circ} \mathrm{C}$ for thirty minutes followed by a boehmite filming process (conducted at relatively lower temperature) to induce an approximately $5 \mu \mathrm{m}$ thick oxide layer on the outer cladding surface. The fuel plates were irradiated in the ATR for 158.2 effective full power days (EFPD). 
Two square segments, each approximately $12.5 \mathrm{~mm}$ in length $\times 12.5 \mathrm{~mm}$ wide, were prepared from the AFIP-1 fuel plate at Idaho National Laboratory containing the Al-2 wt $\%$ Si matrix composition. The midplane of the low burnup sample (referred to as TL) was located $23 \mathrm{~cm}$ from the top of the fuel plate (edge with the plate identification stamp) while the midplane of the high burnup sample (referred to as TK) was located $4.5 \mathrm{~cm}$ from the bottom of the fuel plate (the edge opposite that with the plate identification stamp). The segments consisted of only the fueled region of the fuel plate, i.e., the AA6061 edges of the fuel plate were trimmed away from the segment.

The fuel segments were shipped to Pacific Northwest National Laboratory where they were sectioned further to produce samples for various thermal and physical measurements. These measurements included optical microscopy to obtain cladding and fuel meat layer thicknesses (line intercept method) and the approximate amount of IL, fuel, and remaining matrix material in the fuel meat (areal fraction method) were determined using a Nikon Digital Camera and Elements v4.0 software package. Results are summarized in Table 1 as average values with standard deviations obtained from multiple measurements. Example optical metallographs of segments TL and TK are provided in Figure 1 and Figure 2, respectively. The metallographs show regions of remaining matrix (for the TL segment), interaction layer formation, and gross porosity that has formed within the interaction layer. Porosity inside the fuel particles is also easily observed from the metallographs. In addition, laser flash analysis to obtain thermal diffusivity, differential scanning calorimetry to obtain specific heat capacity, and pycnometry to obtain density were performed. Specific details on the experiments and individual measurements can be found in Reference 10 .

The measurements reported in Reference 10 were used to determine the thermal conductivity of both segments as a function of temperature and have been reported in Reference 11. These results have been used for comparison to the model described in this paper.

\section{CALCULATION}

The thermal conductivity degradation was calculated as a function of temperature and burnup according to the general flow chart provided in Figure 3. At the core of this flow chart is a model described and validated previously in Reference 8 for unirradiated U-Mo dispersion fuel samples. Aspects of that model are summarized here for clarity, along with the modifications that have been made to incorporate the influence of burnup / fission density.

\section{Inputs}

Fuel plate fission power density, surface heat flux, fuel meat fission density, and coolant temperature were obtained for each sample location as a function of time from Reference 12. The fuel plate fission power density and fuel meat fission density were corrected for 
the as-fabricated fuel meat thickness $(\sim 561 \mu \mathrm{m})$. The average fuel particle diameter was assumed as $67 \mu \mathrm{m}$. While it is likely that the fuel particles used to fabricate the fuel plates consisted of a distribution of various sizes, the current model assumed the reported average fuel particle diameter, since information on the actual fuel particle size distribution was unavailable. The fuel particle fission density was determined by dividing the fuel meat fission density by 0.539 , or the volume fraction of fuel in the asfabricated meat. The remaining inputs are discussed in the following sections where they are introduced into the model.

\section{Swelling}

The fuel meat will swell during irradiation, ultimately affecting the thickness of the fuel meat $(a)$. Overall fuel swelling in percent as a function of fission density, $\left(\Delta V / V_{0}\right)_{F}$, can be determined from Equation 1 [13]. While the cladding may also swell during irradiation, the impact is considered negligible in comparison to fuel meat swelling. Thus, the thickness of the cladding on one side $(b)$ was assumed as constant in the model and half of the calculated cladding thickness reported in Table 1 (one side) was used. Comparing the nominal cladding thickness to the experimental thickness measurements of the cladding reported in Table 1 indicates that this is a reasonable assumption. Thus, the parameter $a$ was updated as a function of fission density by determining the amount of fuel swelling (in percent) and increasing the nominal fuel meat thickness by this amount as a function of irradiation time.

$$
\begin{aligned}
& \left(\frac{\Delta V}{V_{0}}\right)_{F}=5.0 f_{d}, \text { for } f_{d} \leq 3 \times 10^{21} \text { fissions } \bullet \mathrm{cm}^{-3} \\
& \left(\frac{\Delta V}{V_{0}}\right)_{F}=15 f_{d}+6.3\left(f_{d}-3\right)+0.33\left(f_{d}-3\right)^{2}, \text { for } f_{d}>3 \times 10^{21} \text { fissions } \bullet \mathrm{cm}^{-3}
\end{aligned}
$$

\section{Volume Fraction}

The interaction layer must consume the fuel, the matrix, or a mixture of both. Initial validation of the model using unirradiated U-Mo dispersion fuel (i.e., as-fabricated) measurements revealed that the best results were obtained when it was assumed that the interaction layer consumed only the matrix [8]. Based on those results, the same assumption was applied in the current model. Thus, the value $R$, defined as the total fuel particle radius plus the interaction layer thickness, will increase at each iteration step as a result of interaction layer formation and growth, while the value $r$, defined as the fuel particle radius, remains constant. Subsequently, the volume fraction of matrix will decrease with formation and growth of an interaction layer and can be determined using Equation 2, where $i$ represents the current iteration step and $v_{m, 0}$ is the original concentration of matrix ( 46.1 vol\% for the cases modeled here).

$v_{m, i}=\left(\frac{R_{i}^{3}}{r_{i}^{3}} * v_{m, 0}\right)+\left(1-\frac{R_{i}^{3}}{r_{i}^{3}}\right)$ 


\section{Thermal Conductivity}

The thermal conductivity of the fuel particle as a function of temperature and fission density (burnup) was determined by performing a multiple second-order polynomial regression on data presented in Reference 14 and represented by Equation 3, where $T_{m}$ is the operational temperature of the fuel meat in ${ }^{\circ} \mathrm{C}$ (ranging from 50 to $300{ }^{\circ} \mathrm{C}$ ) and $f$ is the fuel particle fission density in fissions ${ }^{\bullet} \mathrm{cm}^{-3}$ (ranging from 0 to $4.08 \times 10^{21}$ fissions ${ }^{\bullet} \mathrm{cm}^{-3}$ ).

$\lambda_{U-M o}\left(T_{m}, f\right)=1.294 \times 10^{-5} * T_{m}^{2}-5.59 \times 10^{-3} * T_{m} * f-1.46 \times 10^{-2} * f^{2}+$ $4.11 \times 10^{-2} * T_{m}-0.741 * f+10.8$

The thermal conductivity of the matrix $\left(\lambda_{A l-x S i}\right)$ was determined from data reported in Reference 15 . The data was fit to a third order polynomial as a function of both $\mathrm{Si}$ concentration ( $x$, in wt $\%$, ranging from 0 to $8 \mathrm{wt} \%)$ and operational temperature of the fuel meat $\left(T_{m}\right.$, in ${ }^{\circ} \mathrm{C}$, ranging from 20 to $\left.350{ }^{\circ} \mathrm{C}\right)$ represented by Equation 4 . The third order polynomial fits to within $\pm 3 \%$ of the experimental data reported in Reference 15 .

$\lambda_{A l-x S i}\left(x, T_{m}\right)=-0.478 * x^{3}+0.702 \times 10^{-3} * x^{2} * T_{m}+50.8 \times 10^{-6} * x * T_{m}^{2}+$ $0.507 \times 10^{-6} * T_{m}^{3}+6.64 * x^{2}-28.2 \times 10^{-3} * x * T_{m}-387 \times 10^{-6} * T_{m}^{2}-29.5 *$ $x+57.3 \times 10^{-3} * T_{m}+248$

The thermal conductivity of the interaction layer as a function of temperature is unknown since there is no available data on the properties of the interaction layers that form between U-Mo alloys and Al matrices. Initial validation of the model using unirradiated U-Mo dispersion fuel measurements revealed that the best results were obtained when the interaction layer thermal conductivity was assumed to be half that of the unirradiated fuel particle. Numerous out-of-pile diffusion studies indicate that the interaction layer consists mostly of (U,Mo)Al $\mathrm{A}_{\mathrm{x}}$ intermetallics, where $x$ is generally 2, 3, or 4 [5]. While thermal conductivity data of $\mathrm{UAl}_{\mathrm{x}}$ compounds as a function of temperature is scarce, it has been reported to range from 4.2 to $8.4 \mathrm{~W} \cdot \mathrm{m}^{-1} \cdot{ }^{\circ} \mathrm{C}^{-1}$ at temperatures between 65 and 93 ${ }^{\circ} \mathrm{C}[16,17]$, which is close to the irradiated fuel particle thermal conductivities for the TK and TL samples discussed here (Equation 3) (i.e., $5.6-7.4 \mathrm{~W} \cdot \mathrm{m}^{-1} \cdot{ }^{\circ} \mathrm{C}^{-1}$ at $75{ }^{\circ} \mathrm{C}$ ). However, the interaction layer composition formed during fabrication (e.g., out-of-pile studies) is known to be very different from the composition formed during irradiation $[5,18]$. Equation 2 was used to determine the average fuel particle plus interaction layer thickness $(R)$ for each experimental fuel segment using the volume fraction of fuel plus interaction layer and volume fraction of fuel reported in Table 1 and the reported average fuel particle diameter of $67 \mu \mathrm{m}$. The interaction layer thickness for each fuel segment was determined by subtracting the average fuel particle radius from the calculated $R$. Based on this approach, the TL fuel segment was determined to possess an interaction layer thickness of approximately $5.76 \mu \mathrm{m}$ while the TK fuel segment was determined to possess an interaction layer thickness of $7.66 \mu \mathrm{m}$. Equations 3-6 were then used to calculate the fuel meat thermal conductivity assuming these interaction layer thicknesses and IL thermal conductivity values were equal to and twice that of the unirradiated fuel particle thermal conductivity (Equation 3 with $f=0$ ) as a function of temperature. The 
results of the calculations compared to the experimental thermal conductivity measurements for both fuel segments are presented in Figure 4.

Observation of Figure 4 suggests that the IL layer thermal conductivity is greater than the unirradiated fuel particle conductivity for the TL fuel segment, and equal to the unirradiated fuel particle conductivity for the TK fuel segment. The best agreement between the model and experimental measurements is obtained when the IL thermal conductivity is assumed to be 1.13 times that of the unirradiated fuel particle (represented by the solid lines in Figure 4 ). The model values are within $\pm 7 \%$ of the TL experimental measurements and within $\pm 14 \%$ of the TK experimental measurements over $0-350{ }^{\circ} \mathrm{C}$ temperature range. The agreement over the $100-200{ }^{\circ} \mathrm{C}$ temperature range (the typical operating fuel meat temperature for dispersion fuel) the model is within $\pm 12 \%$ of the experimental measurements for both samples. Of note is that the assumed IL thermal conductivity varies between 2-4 times that of the irradiated fuel particle thermal conductivity. Scanning thermal diffusivity microscope measurements conducted on an irradiated dispersion fuel sample showed that the thermal diffusivity of the IL was roughly four to eight times that of the irradiated fuel particles [19], suggesting that the assumption is reasonable for the current work. Thus, for the ensuing calculations, the IL thermal conductivity was assumed to be 1.13 times that of the unirradiated fuel particle thermal conductivity.

An expression for the equivalent conductivity of a coated sphere subjected to axial heat flow was incorporated into the calculations obtained following the derivation from heat transport equations, summarized by Badrinarayan and Barlow [20] and shown in Equation 5.

$\lambda_{e q}=\frac{R}{\left\{\left(\frac{2 R}{a}\right) \ln \left[\frac{(a R+b)}{(a(R-r)+b)}\right]+\left(\frac{b}{a^{2}}\right) \ln \left[\frac{(a R+b)}{(a(R-r)+b)}\right]+\left(\frac{R-r}{\lambda_{I L}}\right)-\left(\frac{r}{a}\right)\right\}}$

where

$a=-\lambda_{d}$

$b=2(R-r) \lambda_{I L}+2 r \lambda_{d}$

In Equation 5, $R$ is the total particle radius including interaction layer, $r$ is the fuel particle radius, $\lambda_{d}$ is the fuel particle thermal conductivity, and $\lambda_{I L}$ is the interaction layer thermal conductivity. The equivalent fuel particle thermal conductivity $\left(\lambda_{e q}\right)$ that includes the influence of the interaction layer formed between the U-Mo fuel particle and surrounding Al-Si matrix is substituted into Equation 6 as the value for $\lambda_{d}$.

Calculation of the effective fuel meat thermal conductivity is based on the Hsu model [21] shown in Equation 6.

$$
\{1-F(e)\} \lambda_{e}^{2}+\left\{\lambda_{d}\left[F(e)-v_{d}\right]+\lambda_{m}\left[F(e)-v_{m}\right]\right\} \lambda_{e}-\lambda_{d} \lambda_{m} F(e)=0
$$


In Equation 6, $\lambda$ is effective thermal conductivity, $v$ is volume fraction of the dispersed fuel phase, $F(e)$ is a function of the eccentricity of the dispersed fuel phase and is designed to take into account the shape and orientation of the phase $(F(e)=1 / 3$ for spheres), and the subscripts $e, m$, and $d$ represent the effective composite, matrix, and dispersed phase, respectively. The Hsu model was selected since it does not assume a continuous matrix, and therefore can be applied in situations where the matrix and dispersed phases cluster and form agglomerates within the composite, as would be expected with high volume fractions of fuel dispersed in a matrix.

Temperature dependent thermal conductivity of the AA6061 cladding $\left(\lambda_{c}\right)$ was determined from values reported in Reference 22.

\section{Temperature}

Coolant temperature $\left(T_{b}\right)$ during the experiments as a function of time was reported in Reference 12. The coolant temperature was relatively consistent throughout irradiation, ranging from $52-55^{\circ} \mathrm{C}$ for the TL fuel segment and $55-61{ }^{\circ} \mathrm{C}$ for the TK fuel segment. The temperature of the outer surface of the fuel plate cladding in contact with the coolant $\left(T_{c}\right)$ as a function of time was determined according to Newton's law of cooling and described by Equation 7 [23].

$q^{\prime \prime}=h\left(T_{c}-T_{b}\right)$

In equation $7, q$ " is the surface heat flux (obtained as a function of time from Reference 12) and $h$ is the heat transfer coefficient, which was assumed to be constant at 3.03 $\mathrm{W} \cdot \mathrm{cm}^{-2} \cdot{ }^{\circ} \mathrm{C}[24]$.

The operational temperature of the fuel meat $\left(T_{m}\right)$ can be determined by Equation 8 [23], where $a$ is the half thickness of the fuel meat, $b$ is the thickness of the cladding on one side, $\lambda_{e}$ is the effective thermal conductivity of the fuel meat (determined from Equation

6) in $\mathrm{W} \bullet \mathrm{cm}^{-1} \bullet{ }^{\circ} \mathrm{C}^{-1}, \lambda_{c}$ is the thermal conductivity of the cladding in $\mathrm{W} \bullet \mathrm{cm}^{-1} \bullet{ }^{\circ} \mathrm{C}^{-1}, c$ is the oxide layer thickness (assumed as $5 \mu \mathrm{m}$ from pre-filming), and $\lambda_{o}$ is the oxide layer thermal conductivity (assumed to be constant at $0.0225 \mathrm{~W} \bullet \mathrm{cm}^{-1} \bullet{ }^{\circ} \mathrm{C}^{-1}$ ).

$T_{m}=T_{c}+q^{\prime \prime}\left(\frac{a}{2 \lambda_{e}}+\frac{b}{\lambda_{c}}+\frac{c}{\lambda_{o}}\right)$

\section{Interaction Layer Thickness}

In order to predict the influence of temperature and burnup on the thermal conductivity degradation of dispersion fuel, primarily as a result of interaction layer formation, the interaction layer thickness $\left(Y_{i}\right.$, in $\left.\mu \mathrm{m}\right)$ must be computed. Because fabrication is conducted at high temperatures, an interaction layer will form between the U-Mo particles and Al-Si matrix $\left(Y_{f a b}^{2}\right.$, in $\left.\mu \mathrm{m}\right)$, which is represented by Equation 9 [25].

$Y_{\text {fab }}^{2}=5.78 \times 10^{11} \exp \left(\frac{-27500}{T}\right) t$ 
In equation $9, t$ is the time in seconds that the fuel plate is subjected to a temperature $T$ in $\mathrm{K}$. According to the fabrication details provided earlier, both fuel segments had an interaction layer thickness of approximately $0.9 \mu \mathrm{m}$.

The interaction layer thickness will grow during irradiation and can be represented by Equation 10, which takes into account the effect of Si addition to the matrix and Mo concentration in the fuel alloy [25].

$Y_{i}^{2}=Y_{i, 0}^{2} * f_{S i} * f_{M o}$

In Equation 10, $Y_{i, 0}$ is the interaction layer thickness for U-Mo particles dispersed in a pure $\mathrm{Al}$ matrix represented by Equation $11, f_{S i}$ is the reduction factor by $\mathrm{Si}$ addition in the Al matrix represented by Equation 12, and $f_{M o}$ is the reduction factor of Mo content in the fuel alloy represented by Equation 13 [25].

$Y_{i, 0}^{2}=2.6 \times 10^{-8} * \dot{f}^{0.5} * \exp \left(\frac{-3850}{T_{m}+273}\right) * \mathrm{t}$

$f_{S i}=\left[1.201-0.00062 *\left(T_{m}+273\right)\right] * \exp \left\{-\left[10.333-0.021 *\left(T_{m}+273\right)\right] *\right.$

$\left.W_{S i}\right\}+\left[0.00062 *\left(T_{m}+273\right)-0.201\right] * \exp \left\{-\left[0.00081 *\left(T_{m}+273\right)-0.302\right] *\right.$

$\left.W_{S i}\right\}$

$f_{M o}=1.35-0.05 * W_{M o}$

In Equations 11 through 13, $\dot{f}$ is the average fuel meat fission density rate in fissions ${ }^{\bullet} \mathrm{cm}^{-}$ ${ }^{3} \cdot \sec ^{-1}$ through time $t$ in seconds (determined from the reported fission power density in Reference 12 as a function of time), $T_{m}$ is the average operational temperature of the fuel meat in ${ }^{\circ} \mathrm{C}$ (described by Equation 8, and less than or equal to $200{ }^{\circ} \mathrm{C}$ ) through time $t, W_{S i}$ is the $\mathrm{Si}$ content in the matrix in wt\% (assumed to be $2 \mathrm{wt} \%$ for these samples, and less than or equal to $8 \mathrm{wt} \%$ ), and $W_{M o}$ is the Mo content in the fuel particles in wt $\%$ (assumed to be $7 \mathrm{wt} \%$ for these samples, and variable between 6 and $10 \mathrm{wt} \%$ ).

The total IL growth $(Y$, in $\mu \mathrm{m})$ accumulating during fabrication and irradiation as a function of time (and subsequent irradiation conditions and calculations) can be obtained from Equation 14 [25].

$Y=\sqrt{Y_{f a b}^{2}+Y_{i}^{2}}$

\section{RESULTS}

Thermal conductivity degradation of the TK and TL fuel segments was calculated as a function of fuel meat fission density and temperature according to the flow chart provided in Figure 3 and the equations described previously. Thermal conductivity of the fuel meat for both the TL and TK samples as a function of fuel meat fission density is 
provided in Figure 5. Included on Figure 5 is the range of experimentally measured fuel meat thermal conductivities at temperatures that bound the calculated fuel meat operating temperature at the end of life fission density.

Observation of Figure 5 suggests that the thermal conductivity of the fuel meat at beginning of life is $60.2 \mathrm{~W} \cdot \mathrm{m}^{-1} \cdot{ }^{\circ} \mathrm{C}^{-1}$ for the TL segment and $62.2 \mathrm{~W} \cdot \mathrm{m}^{-1} \cdot{ }^{\circ} \mathrm{C}^{-1}$ for the TK segment, with a calculated beginning of life fuel meat temperature of $138{ }^{\circ} \mathrm{C}$ and $185{ }^{\circ} \mathrm{C}$ respectively. Thermal conductivity measurements conducted on unirradiated dispersion fuel containing 37.6 volume percent of U-8wt\% Mo fuel particles in an Al matrix with an interaction layer thickness of $1.20 \mu \mathrm{m}$ (comparable to the interaction layer thickness during fabrication) ranged from $86.3-88.5 \mathrm{~W} \cdot \mathrm{m}^{-1} \cdot{ }^{\circ} \mathrm{C}^{-1}$ over $100-200{ }^{\circ} \mathrm{C}[26]$, in acceptable agreement with the beginning of life values calculated using the current model. The difference in volume fraction of fuel (i.e., $37.6 \%$ v. $53.9 \%$ ) likely contributes to the difference between the calculated and reported values in literature. The model reasonably predicts the fuel meat thermal conductivity at end of life for both samples, within $\pm 11 \%$ of the experimental measurements. The calculated fuel meat thermal conductivity at end of life is at the upper end of the experimental measurements for both fuel segments.

The volume fraction of fuel plus interaction layer and the interaction layer thickness as a function of fuel meat fission density for both samples is provided in Figure 6 . Included on the figure is the experimentally determined end of life volume fraction of fuel plus interaction layer reported in Table 1.

Observation of Figure 6 shows acceptable agreement between the calculated and experimentally measured volume fraction of fuel plus interaction layer. The Al-2Si matrix of the TK sample has been completed consumed by interaction layer at a fuel meat fission density of $5.31 \times 10^{20}$ fissions $\mathrm{cm}^{-3}$, owing to the much higher operational temperature for this particular fuel segment. The interaction layer thickness formed for the TK fuel segment was calculated as $7.66 \mu \mathrm{m}$ at the time the matrix was completely consumed, and remained constant for increasing fuel meat fission density since the interaction layer was assumed to consume the matrix only. The theoretical maximum interaction layer that can be formed between two neighboring fuel particles for a given volume fraction of fuel (where 0.74 is considered the maximum as a FCC packing fraction) can be determined from Equation 15 [25]. Calculation of the maximum interaction layer thickness for the TK fuel segment using Equation 15 is $7.48 \mu \mathrm{m}$, well within $\pm 5 \%$ of the interaction layer thickness determined by the model using Equations 914.

$Y_{i, \max }=\left(\frac{1}{\sqrt{2}} \sqrt[3]{\frac{16 \pi}{3} \frac{1}{v_{f, 0}}}-2\right) r$

The calculated operational fuel meat temperature of the TK and TL fuel segments is provided in Figure 7 as a function of fuel meat fission density. The TK fuel segment operated at temperatures approximately $12-52{ }^{\circ} \mathrm{C}$ hotter than the TL fuel segment as a result of the higher fission power density experienced by the TK fuel segment during 
irradiation, especially early in the irradiation. The operational fuel meat temperature of the TK fuel segment increased sharply as the matrix was consumed by interaction layer as a result of the peak fission power density, and then began to decrease as a result of decreasing fission power density. The calculated end of life fuel meat thickness was 639 $\mu \mathrm{m}$ for the TL fuel segment and $664 \mu \mathrm{m}$ for the TK fuel segment, well within $\pm 5 \%$ of the experimentally measured fuel meat thicknesses reported in Table 1.

\section{DISCUSSION}

The model described in this work reasonably predicts the thermal conductivity of U-Mo fuel particles dispersed in an Al-2Si matrix as a function of fission density, at least when compared to available experimental measurements. The results are also in acceptable agreement with two- and three-dimensional microstructure based finite element thermal analyses studies conducted on U-Mo dispersion fuels, where the effective thermal conductivity (for a two-dimensional case) ranged from $16-36 \mathrm{~W} \cdot \mathrm{m}^{-1} \cdot{ }^{\circ} \mathrm{C}^{-1}$ for an interaction layer thickness of $5 \mu \mathrm{m}$ (similar to sample TL) and $9.84-11.78 \mathrm{~W} \cdot \mathrm{m}^{-1} \cdot{ }^{\circ} \mathrm{C}^{-1}$ for a fully interacted matrix (similar to sample TK) [27]. However, observation of the results in Figure 5 revealed a slight over prediction in the end of life fuel meat thermal conductivity values for both samples, more so for the TK fuel segment ( 11\% deviation), when compared to the available experimental measurements.

Based on the minor deviation observed, the sensitivity of the model was investigated to understand the influence that process variables (i.e., average fuel particle diameter, volume fraction of fuel, Si content in the matrix, and Mo content in the fuel alloy) on interaction layer formation and subsequently fuel meat thermal conductivity. For each of the ensuing sensitivity discussions, the irradiation history of the TL and TK fuel segments was assumed to be constant, although it is recognized that irradiation conditions would likely change based on the as-fabricated inputs, e.g., a higher volume fraction of fuel will likely lead to higher fission power densities and surface heat fluxes, etc.

Finer fuel particles would result in faster consumption of the Al-2Si matrix as a result of increased surface area for interaction layer formation and higher fuel meat temperatures, an observation also noted during modeling studies by Ryu et al. [6]. Concomitantly, the resultant fuel meat thermal conductivity at end of life would be lower. Atomized U-Mo fuel particles typically have a wide particle size distribution. This is evident in the example optical microscopy images provided in Figure 1 and Figure 2. The use of an average fuel particle diameter simplifies the model tremendously, although future improvements may consider a fuel particle size distribution if improved calculation uncertainty is warranted. However, this must be coupled with improved pre-irradiation fuel particle characterization and fuel plate characterization, neither of which was extensive enough for the AFIP-1 experiment to include here, as well as additional irradiated dispersion fuel thermo-physical property measurements. The sensitivity of the fuel meat thermal conductivity and interaction layer thickness to average fuel particle diameter is presented graphically for both fuel segments in Figure 8.

Observation of Figure 8 clearly shows the sensitivity of calculated fuel meat thermal conductivity on average fuel particle diameter, as long as the matrix is not completely 
consumed. For example, use of an average fuel particle diameter of $47 \mu \mathrm{m}$ for the TK and TL segments results in complete consumption of the matrix and concomitantly comparable end of life fuel meat thermal conductivities. However, as the average fuel particle diameter is increased beyond $47 \mu \mathrm{m}$, the interaction layer thickness begins to decrease for the TL segment, but not for the TK fuel segment. This indicates the influence that fission density rate and heat flux have on interaction layer formation. A modest decrease in the interaction layer thickness, e.g. $1 \mu \mathrm{m}$, can result in a near tripling of the end of life fuel meat thermal conductivity. However, for the TK fuel segment that was operated at higher surface heat flux, there is no reduction of interaction layer thickness until a particle size greater than $127 \mu \mathrm{m}$ was used.

Similarly, the volume fraction of fuel particles was assumed as from the available asfabricated fuel plate data and to be uniform throughout the fuel meat. It is probable that there is also a distribution in the fuel loading throughout the fuel meat. An actual lower volume fraction of fuel particles would have a similar effect to the use of coarser fuel particles in the model, i.e., slower consumption of the Al-2Si matrix and higher end of life fuel meat thermal conductivities. Ryu et al. also showed an increase in the volume fraction of dispersed phase resulted in higher centerline fuel temperatures for a constant particle size [6]. The sensitivity of the fuel meat thermal conductivity and interaction layer thickness to volume fraction of fuel particles is presented graphically for both fuel segments in Figure 9.

Figure 9 shows that the end of life fuel meat thermal conductivity can be influenced by relatively minor changes in volume fraction of fuel particles at low surface heat fluxes and moderate burnups (i.e., TL segment). However, as with the average fuel particle diameter, the volume fraction of fuel has no influence on the TK segment as a result of the higher surface heat flux and fission density that this segment experienced. It is interesting to note, at least for the TL segment, that increasing the average fuel particle diameter by $60 \mu \mathrm{m}$ (to $127 \mu \mathrm{m}$ ) has a similar influence on fuel meat thermal conductivity and interaction layer thickness as decreasing the volume fraction of fuel by $10 \%$ (to $43.9 \%$ ), suggesting that these two variables are likely the most influential in controlling thermal conductivity degradation and interaction layer thickness growth.

Equation 10 allows for the influence of Si content in the matrix and Mo content in the fuel particle alloy on fuel meat thermal conductivity degradation and interaction layer thickness to be assessed. Figure 10 presents the end of life fuel meat thermal conductivity and interaction layer thickness for both fuel segments as a function of $\mathrm{Si}$ concentration in the matrix (left; assuming U-7wt\% Mo fuel particles) and Mo concentration in the fuel (right; assuming $2 \mathrm{wt} \% \mathrm{Si}$ in the matrix). The volume fraction of fuel in both fuel segments was assumed to be $53.9 \%$, average fuel particle diameter 67 $\mu \mathrm{m}$, and the irradiation conditions kept the same for each fuel segment as modeled previously.

The influence of Si content on calculated end of life fuel meat thermal conductivity and interaction layer thickness is apparent for the TL fuel segment. Additions of up to 4wt\% $\mathrm{Si}$ in the matrix dramatically decrease interaction layer formation (by approximately 
$50 \%$ ) and subsequently increase end of life fuel meat thermal conductivity compared to the case where a pure Al matrix is used. However, there is no influence of Si content in the matrix on interaction layer thickness formation, up to $6 \mathrm{wt} \% \mathrm{Si}$, for the TK fuel segment, and no significant change in the end of life fuel meat thermal conductivity. The matrix is completely consumed even with $\mathrm{Si}$ additions up to $6 \mathrm{wt} \%$. This again points to the importance of irradiation conditions on interaction layer growth and subsequent fuel meat thermal conductivity degradation. For fuel plates subjected to relatively moderate burnup and heat flux conditions (e.g., less than $2.78 \times 10^{21}$ fissions ${ }^{\bullet} \mathrm{cm}^{-3}$ and $236 \mathrm{~W} \bullet \mathrm{cm}^{-}$ ${ }^{2}$ ), Si additions of $4 \mathrm{wt} \%$ or greater to the matrix are effective. However, for fuel plates subjected to slightly more severe burnup and heat flux conditions (e.g., $3.5 \times 10^{21}$ fissions $\boldsymbol{c}^{-3}$ and $315 \mathrm{~W} \cdot \mathrm{cm}^{-2}$ ), the addition of Si has a relatively insignificant effect. Similarly, increasing additions of Mo to the fuel particle above $7 \mathrm{wt} \%$ have a relatively minimal influence on calculated end of life fuel meat thermal conductivity and interaction layer thickness for the TL fuel segment, and virtually no influence on the TK fuel segment.

The sensitivity analysis can be used to partially explain the behavior of high density dispersion fuel tests conducted as part of a European fuel qualification effort summarized in Reference 28. As part of these tests, fuel plates containing $2 \mathrm{wt} \%$ Si performed well at moderate heat flux $\left(\sim 200-270 \mathrm{~W} \bullet \mathrm{cm}^{-2}\right)$, similar to the TL fuel segment used for comparison here. However, increasing the Si concentration to 6\% for fuel plates operated at higher heat flux $\left(470 \mathrm{~W} \cdot \mathrm{cm}^{-2}\right)$ did not perform well and the fuel plates were observed to have pillowed after peak burnup to $71 \%{ }^{235} \mathrm{U}$. Further increase in $\mathrm{Si}$ concentration to $12 \mathrm{wt} \%$ had an even more deleterious effect on fuel performance, and peak burnups of only $30-54 \%{ }^{235} \mathrm{U}$ were achieved before the irradiation had to be stopped. The complete reason for this behavior is not entirely clear and has been the subject of much investigation over the last decade. However, given the minimal influence of $\mathrm{Si}$ concentration on fuel meat thermal conductivity and interaction layer thickness (shown in Figure 10), it may be that this behavior is driven less by the formation of an interaction layer during irradiation and more by the concentration of $\mathrm{Si}$ present within the interaction layer that affects the material characteristics of the layer, as described by Keiser et al. [9].

The calculated peak operational fuel temperature of the fuel segments appears to be relatively unaffected by interaction layer growth and thermal conductivity degradation. For the TK fuel segment, complete consumption of the matrix results in a peak operational fuel temperature of $204{ }^{\circ} \mathrm{C}$. For the cases where the matrix was not completely consumed, the peak operational fuel temperature decreased by only approximately $10{ }^{\circ} \mathrm{C}$. For the TL fuel segment, the peak operational fuel temperature ranged over $14{ }^{\circ} \mathrm{C}$ for the different cases investigated. This observation is similar to that made by Medvedev who determined that the maximum centerline temperature of platetype dispersion fuels was insensitive to in-pile degradation of the fuel thermal conductivity as the result of the very thin fuel meat thickness compared to the cladding [24]. Centerline temperature is mainly dependent upon fission power density. However, even modest temperature rises could have deleterious performance effects as a result of irradiation conditions. A portion of fission fragments born in the U-7Mo fuel particles 
will recoil into the matrix material. These fission fragment atoms either take up positions close to the end of their recoil range or diffuse to the most stable configuration [29]. Diffusion is dependent upon temperature and energy of activation for diffusion in the surroundings. If the temperature is high enough to permit movement of the inert gaseous fission products, nucleation and growth of gas pockets will form at a specific burnup, especially given the relatively low solubility of fission gases in typical matrix materials, such as Al. The net result is formation of large pores within the fuel meat, which was observed in both metallographs shown in Figure 1 and Figure 2, more so for the TK sample, especially at regions where the interaction layers begin to overlap. Formation of these large pores is a concern since blisters could result on the surface of the fuel plate with increased operational fuel meat temperature and reduced matrix / cladding strength and/or increased fission gas generation with continued burnup, ultimately indicating the onset of fuel failure. While the yield strength of the matrix is likely still adequate for the two fuel segments used in the current work, an increase in fuel meat temperature above $200{ }^{\circ} \mathrm{C}$, either through use of finer fuel particles or operation at even higher heat fluxes (e.g. $500 \mathrm{~W} \bullet \mathrm{cm}^{-2}$ ), the yield strength of the matrix would likely fall below a critical level to contain coalescence and growth of fission gas bubbles.

The current model does not take the porosity that may be present in the fuel meat post fabrication or that forms during irradiation into account. Porosity that forms inside the fuel particle as a result of irradiation has been considered in Equation 4 and compared to a separate model in Reference 14, and through the incorporation of the increasing fuel meat thickness as a function of fission density on account of fuel swelling. Improved pre-irradiation characterization information, particularly density, is needed in order to improve the model further, as there is currently insufficient information to address formation of gross porosity formation in the present model. The influence of matrix porosity formation is not as significant for the current comparisons, e.g., samples operated at moderate heat flux, but could become much more important for samples operated at higher heat fluxes, e.g. $>400 \mathrm{~W} \cdot \mathrm{cm}^{-2}$.

Furthermore, the current model assumes that the interaction layer consumes the matrix only. While this assumption has produced reasonable results when compared to both unirradiated and now irradiated fuel samples, it is likely that some portion, although relatively minor, of the fuel particles must be consumed. The formation of $\mathrm{UAl}_{\mathrm{x}}$ intermetallics, which have been observed in unirradiated and irradiated samples, would not be possible without some portion of fuel particle consumption. However, sufficient data and characterization does not exist to reasonably challenge the basic assumption used in the current model. Given the $\mathrm{U}$ atomic percent differences between $\mathrm{UAl}_{3}$ and U-Mo fuel particle, it is reasonable that only small amounts of fuel are actually consumed and not significant enough to influence the model results. Furthermore, an individual fuel particle will swell during irradiation. Swelling of the overall fuel plate was considered in the model, but not for each individual fuel particle. It is hypothesized that the amount of fuel swelling is of the same order of magnitude as the thickness of fuel consumed via interaction layer formation, such that these two mechanisms nearly cancel out so that the fuel particle diameter would remain relatively constant. 
The interaction layer thermal conductivity was assumed as 1.13 times that of the unirradiated fuel particle thermal conductivity based on a best fit with the available experimental data. Again, while this assumption has produced reasonable results when compared to both unirradiated and now irradiated fuel samples, it is probable that compositional changes influenced by operational temperature and irradiation temperatures will result in different thermal property behavior of the interaction layer. For example, interaction layer composition has been shown to be different depending upon the operational fuel meat temperature, with $x$ being closer to 3 in the hotter region (applicable to sample TK) and 4 in the cooler region (applicable to TL) [30]. This is likely the reason why assuming interaction layer thermal conductivity equal to unirradiated fuel particle thermal conductivity yields better agreement with the TK segment than the TL segment (Figure 4). The authors could find no data or observations that support interaction layer thermal conductivity as a function of composition, and it is therefore not possible at this time to challenge the assumption applied in the current model, especially since the assumption is most valid within the typical operational fuel meat temperature range of $100-200{ }^{\circ} \mathrm{C}$.

\section{CONCLUSIONS}

A simple model based on the Hsu equation described previously has been extended to account for interaction layer formation during irradiation with consideration of Si content in the matrix and Mo content of the fuel particles. The model has been updated with new thermal property information on Al-Si matrices and irradiated U-Mo fuel. Results of the model were compared to recent experimental measurements of nominally $53.9 \mathrm{vol} \%$ of approximately $67 \mu \mathrm{m}$ diameter U-7Mo fuel particles dispersed in an Al-2wt\% Si matrix and irradiated at moderate heat flux and burnup. The model shows acceptable agreement with the experimental measurements. A sensitivity analysis of the model on process parameters was conducted to describe the minor differences between the calculations and experimental measurements. The model is most sensitive to the average fuel particle diameter, which will vary as a result of fabrication method and parameters. However, the model can be used to tighten the range of fuel particles allowed in the fabrication specification. The model is relatively sensitive to the volume fraction of fuel dispersed in the matrix, which will likely vary over relatively short distances given typical dispersion fuel fabrication operations (i.e., rolling). The model does not appear sensitive to Si additions to the matrix, depending upon the fission density and heat flux that the fuel is operated at. At low fission densities and heat fluxes, additions of up to $4 \mathrm{wt} \%$ Si to the matrix appear beneficial, after which there is very minimal effect. Additions of up to $6 \mathrm{wt} \% \mathrm{Si}$ to the matrix are necessary to negate full matrix consumption at higher fission densities and heat fluxes, although the improvement in fuel thermal conductivity degradation is minimal. The model also does not appear sensitive to Mo additions to the fuel particle beyond $7 \mathrm{wt} \%$. The interaction layer thermal conductivity used in the current work for irradiated fuel is higher than that typically assumed for unirradiated fuel. The differences in interaction layer composition are likely responsible for the use of higher thermal conductivities, but cannot be verified without additional experimental measurements, which are unavailable at the present time. The model described in this paper can be used to evaluate the combination of parameters typically employed during 
dispersion fuel fabrication to achieve a desired performance, or at least provide insight into the range of conditions that could begin to result in deleterious fuel performance. 


\section{ACKNOWLEDGEMENTS}

The authors would like to acknowledge Dr. Walter Luscher for his review of the manuscript and helpful discussion. The authors would also like to acknowledge staff at Idaho National Laboratory, Technische Universität München, and Pacific Northwest National Laboratory involved in the experimental measurements used for comparison in the current work. This work was conducted at Pacific Northwest National Laboratory operated by Battelle for the United States Department of Energy under Contract DEAC05-76RL01830. The work is in support of the National Nuclear Security Administration Office of Material Management and Minimization Reactor Conversion Program.

This paper was prepared as an account of work sponsored by an agency of the United States Government. Neither the United States Government nor any agency thereof, nor Battelle Memorial Institute, nor any of their employees, makes any warranty, express or implied, or assumes any legal liability or responsibility for the accuracy, completeness, or usefulness of any information, apparatus, product, or process disclosed, or represents that its use would not infringe privately owned rights. Reference herein to any specific commercial product, process, or service by trade name, trademark, manufacturer, or otherwise does not necessarily constitute or imply its endorsement, recommendation, or favoring by the United States Government or any agency thereof, or Battelle Memorial Institute. The views and opinions of authors expressed herein do not necessarily state or reflect those of the United States Government or any agency thereof. 


\section{REFERENCES}

1. D. Stahl, Fuels for Research and Test Reactors, Status Review: July 1982, Argonne National Laboratory Report ANL—83-5 (1982).

2. A. Glaser, About the Enrichment Limit for Research Reactor Conversion: Why 20\%?, 27 $7^{\text {th }}$ International Meeting on Reduced Enrichment for Research and Test Reactors, Boston, MA (2005).

3. International Atomic Energy Agency, Advanced Fuel Cycle and Reactor Concepts, Report of the International Fuel Cycle Evaluation (INFCE) Working Group 8, Vienna, Austria, STI/PUB/534 (1980).

4. A. Boltax, Behavior of Fissionable Material Under Irradiation, in: A.R. Kaufman (Ed.), Nuclear Reactor Fuel Elements, John Wiley \& Sons Inc., Hoboken, NJ, 1962, Chapter 9.

5. D.L. Porter and A. Ewh, Interaction Layer Characteristics in U-xMo Dispersion/Monolithic Fuels, Idaho National Laboratory Report INL/EXT-1017972, Rev. 1, November 2010.

6. H.J. Ryu, Y.S. Kim, J.M. Park, H.T. Chae, and C.K. Kim, Performance Evaluation of U-Mo/Al Dispersion Fuel by Considering a Fuel-Matrix Interaction, Nuc. Eng. Tech. 40 (5) (2008) 409-418.

7. A.F. Williams, B.W. Leitch, and N. Wang, A Microstructural Model of the Thermal Conductivity of Dispersion Type Fuels with a Fuel Matrix Interaction Layer, Nuclear Engineering and Technology 45 (7) (2013) 839-846.

8. D.E. Burkes, A.M. Casella, and T.K. Huber, "Modeling the influence of interaction layer formation on thermal conductivity of U-Mo dispersion fuel," J. Alloy Comp. 618 (2015) 7-13.

9. D.D. Keiser Jr., J.-F. Jue, A.B. Robinson, P. Medvedev, J. Gan, B.D. Miller, D.M. Wachs, G.A. Moore, C.R. Clark, M.K. Meyer, and M.R. Finlay, "Effects of irradiation on the microstructure of U-7Mo dispersion fuel with Al-2Si matrix," J. Nucl. Mater. 425 (2012) 156-172.

10. D.E. Burkes, A.J. Casella, E.C. Buck, A.M. Casella, M.K. Edwards, P.J. MacFarlan, K.N. Pool, F.N. Smith, and F.H. Steen, LEU-Mo Fuel Out-of-Pile Characterization for TUM: Final Report, PNNL-23620, Pacific Northwest National Laboratory, September 2014.

11. T.K. Huber, H. Breitkreutz, W. Petry, C. Reiter, S. Elgeti, D.E. Burkes, A.J. Casella, A.M. Casella, F.N. Smith, and D.M. Wachs, "The Thermal Properties of Fresh and 
Spent U-Mo Fuels: An Overview," Transactions of the European Research Reactor Conference (RRFM) 2015, Bucharest, Romania, April 19-23, 2015.

12. D.M. Perez, M.A. Lillo, G.S. Chang, G.A. Roth, N.E. Woolstenhulme, and D.M. Wachs, AFIP-1 Irradiation Summary Report, INL/EXT-11-22045, Idaho National Laboratory, Idaho Falls, May 2011.

13. Y.S. Kim and G.L. Hofman, "Fission product induced swelling of U-Mo alloy fuel," J. Nucl. Mater. 419 (2011) 291-301.

14. D.E. Burkes, A.M. Casella, A.J. Casella, E.C. Buck, K.N. Pool, P.J. MacFarlan, M.K. Edwards, and F.N. Smith, "Thermal properties of U-Mo alloys irradiated to moderate burnup and power", J. Nucl. Mater. 464 (2015) 331-341.

15. A. Wolf, Influence of the Si content in the matrix material in terms of thermal conductivity of disperse UMo fuels," B.Sc. Thesis (in German), Technische Universitat Munchen, Munich, Germany, August 22, 2014, ftp://ftp.frm2.tum.de/outgoing/hbreitkr/bac_awolf.pdf accessed on May 14, 2015.

16. A. Jesse, G. Ondracek, and F. Thümmler, Preliminary Studies of the Fabrication of $\mathrm{UAl}_{4}$-Al Test-Plates by Powder-Metallurgical Techniques, Powder Metall. 14 (28) (1971) pp. 289-297.

17. T.I. Jones, K.N. Street, J.A. Scoberg, and J. Baird, Relation between microstructure and thermal conductivity in Aluminum-Uranium alloys, Can. Metall. Quarterly 2 (1) (1963) pp. 53-71

18. A. Leenaers, S. Van de Berghe, J. Van Eyken, E. Koonen, F. Charollais, P. Lemoine, Y. Calzavara, H. Guyon, C. Jarousse, D. Geslin, D. Wachs, D. Keiser, A. Robinson, G. Hofman, and Y.S. Kim, "Microstructural evolution of U(Mo)-Al(Si) dispersion fuel under irradiation - Destructive analyses of the LEONIDAS E-FUTURE plates," J. Nucl. Mater. 441 (2013) 439-448.

19. T.K. Huber, M.K. Fig, D. Garrett, J.R. Kennedy, A.B. Robinson, and D.M. Wachs, "First Results of Scanning Thermal Diffusivity Microscope (STDM) Measurements on Irradiated Monolithic and Dispersion Fuel," INL/EXT-12-26708, Idaho National Laboratory, Idaho Falls, ID, July 2012.

20. B. Badrinarayan and J.W. Barlow, Prediction of the Thermal Conductivity of Beds Which Contain Polymer Coated Metal Particles, Solid Freeform Fabrication (SFF) Symposium (1990) 91-98.

21. W.Y. Hsu and T. Berzins, Percolation and effective-medium theories for perfluorinated ionomers and polymer composites, J. Polym. Sci. Polym. Phys. Ed. 23 (1985) 933-953. 
22. DOD - U.S. Department of Defense. 1998. Metallic Materials and Elements for Aerospace Vehicle Structures. MIL-HDBK-5H, U.S. Department of Defense, Washington, D.C.

23. J.R. LaMarsh, Introduction to Nuclear Engineering, Addison-Wesley Publishing Company, Reading, MA (1977) p. 322-333.

24. P.G. Medvedev, Effect of In-Pile Degradation of the Meat Thermal Conductivity on the Maximum Temperature of the Plate-Type U-Mo Dispersion Fuels, $31^{\text {st }}$ International Meeting on Reduced Enrichment for Research and Test Reactors, Beijing, China, November 1-5, 2009.

25. Y.S. Kim, G.L. Hofman, H.J. Ryu, J.M. Park, A.B. Robinson, and D.M. Wachs, Modeling of Interaction Layer Growth Between U-Mo Particles and an Al Matrix, Nucl. Eng. Tech. 45 (7) (2013) 827-838.

26. S.H. Lee, J.C. Kim, J.M. Park, C.K. Kim, and S.W. Kim, "Effect of Heat Treatment on Thermal Conductivity of U-Mo/Al Alloy Dispersion Fuel," Int. J. Thermophysics 24 (5) (2003) 1355-1371.

27. B Coulson, "Two- and Three-Dimensional Thermal Analyses of Uranium/Molybdenum Dispersion Fuel Microstructures," M.Sc. Thesis, Colorado School of Mines, Golden, Co, December 21, 2012.

28. H. Breitkreutz, R. Jungwirth, A. Rohrmoser, W. Petry, S. Van Den Berghe, A. Leenaers, E. Koonen, P. Lemoine, M. Ripert, H. Palancher, M.-C. Anselmet, C. Jarousse, B. Stepnik, D. Geslin, Y. Calzavara, and H. Guyon, "The Development of Disperse UMo as a High Performance Research Reactor Fuel in Europe," Transactions of the European Research Reactor Conference (RRFM) 2013, St. Petersburg, Russia, April 21-25, 2013.

29. J.P. Howe, "The Metallurgy of Reactor Fuels," Proc. Of the International Conf. on the Peaceful Uses of Atomic Energy, Vol. 9 Reactor Technology and Chemical Processing (1956), pp. 179-195.

30. J.M. Park, H.J. Ryu, Y.S. Lee, B.O. Yoo, Y.H. Jung, C.K. Kim, and Y.S. Kim, "PIE Results of the KOMO-3 Irraidation Tests," Transactions of the European Research Reactor Conference (RRFM) 2008, Hamburg, Germany, March 2-5, 2008. 


\section{LIST OF TABLES}

Table 1. Optical Microscopy Results on Both Segments Analyzed as Part of This Work. The number of measurements used to determine the average and standard deviation values are provided in parentheses.

\begin{tabular}{|l|c|c|c|}
\hline Fuel Segment & $\begin{array}{c}\text { Nominal (as- } \\
\text { fabricated) }\end{array}$ & TL & TK \\
\hline Fuel meat thickness $(\mu \mathrm{m})$ & 561.3 & $595.4 \pm 33.3(77)$ & $666.5 \pm 33.2(188)$ \\
\hline $\begin{array}{l}\text { Total segment thickness } \\
(\mu \mathrm{m})\end{array}$ & $1221.7(\mathrm{max})$ & $1306.2 \pm 2.2(4)$ & $1320.7 \pm 5.5(4)$ \\
\hline Cladding thickness $(\mu \mathrm{m}) *$ & 660.4 & $710.8 \pm 33.4$ & $654.2 \pm 33.7$ \\
\hline $\begin{array}{l}\text { Fuel particle volume } \\
\text { fraction }\end{array}$ & $53.9 \%$ & $50.9 \%$ & $49.1 \%$ \\
\hline $\begin{array}{l}\text { Interaction layer volume } \\
\text { fraction }\end{array}$ & $0 \%$ & $35.8 \%$ & $50.9 \%$ \\
\hline Matrix volume fraction & $46.1 \%$ & $13.2 \%$ & $0 \%$ \\
\hline *Determined by subtracting fuel meat thickness from total segment thickness \\
\hline
\end{tabular}




\section{FIGURE CAPTIONS}

Figure 1. Example optical metallographs obtained from Segment TL.

Figure 2. Example optical metallographs obtained from Segment TK.

Figure 3. Flow Chart of the Fuel Meat Thermal Conductivity Model

Figure 4. Comparison of experimental and calculated (using Equations 3-6) fuel meat thermal conductivity as a function of temperature for both fuel segments (TL - red; TK - blue). The dashed lines represent an assumed IL thermal conductivity equal to that of the unirradiated fuel particle, while the dotted lines represent an assumed IL thermal conductivity twice that of the unirradiated fuel particle. The solid line represents the best agreement for both fuel segments when the IL thermal conductivity is $\mathbf{1 . 1 3}$ times that of the unirradiated fuel particle.

Figure 5. Calculated fuel meat thermal conductivity as a function of fuel meat fission density compared to experimental measurements at end of life.

Figure 6. Calculated volume fraction of fuel plus interaction layer compared to experimental measurements at end of life and calculated interaction layer thickness as a function of fuel meat fission density.

Figure 7. Calculated operational fuel meat temperature of the TK and TL fuel segments as a function of fuel meat fission density.

Figure 8. Calculated end of life fuel meat thermal conductivity (solid lines) and interaction layer thickness (dotted lines) as a function of average fuel particle diameter for the TK (red) and TL (blue) fuel segments. The calculations assume a volume fraction of fuel of 0.539 .

Figure 9. Calculated end of life fuel meat thermal conductivity (solid lines) and interaction layer thickness (dotted lines) as a function of volume fraction of fuel for the TK (red) and TL (blue) fuel segments. The calculations assume an average fuel particle diameter of $67 \mu \mathrm{m}$.

Figure 10. Calculated end of life fuel meat thermal conductivity (solid lines) and interaction layer thickness (dotted lines) for the TK (blue) and TL (red) fuel segments as a function of Si content in the matrix (left) and Mo content in the fuel particle (right). Calculations as a function of $\mathrm{Si}$ concentration in the matrix assume U-7wt\% Mo fuel particles, while calculations as a function of Mo concentration in the fuel assume an Al-2wt\% Si matrix. 


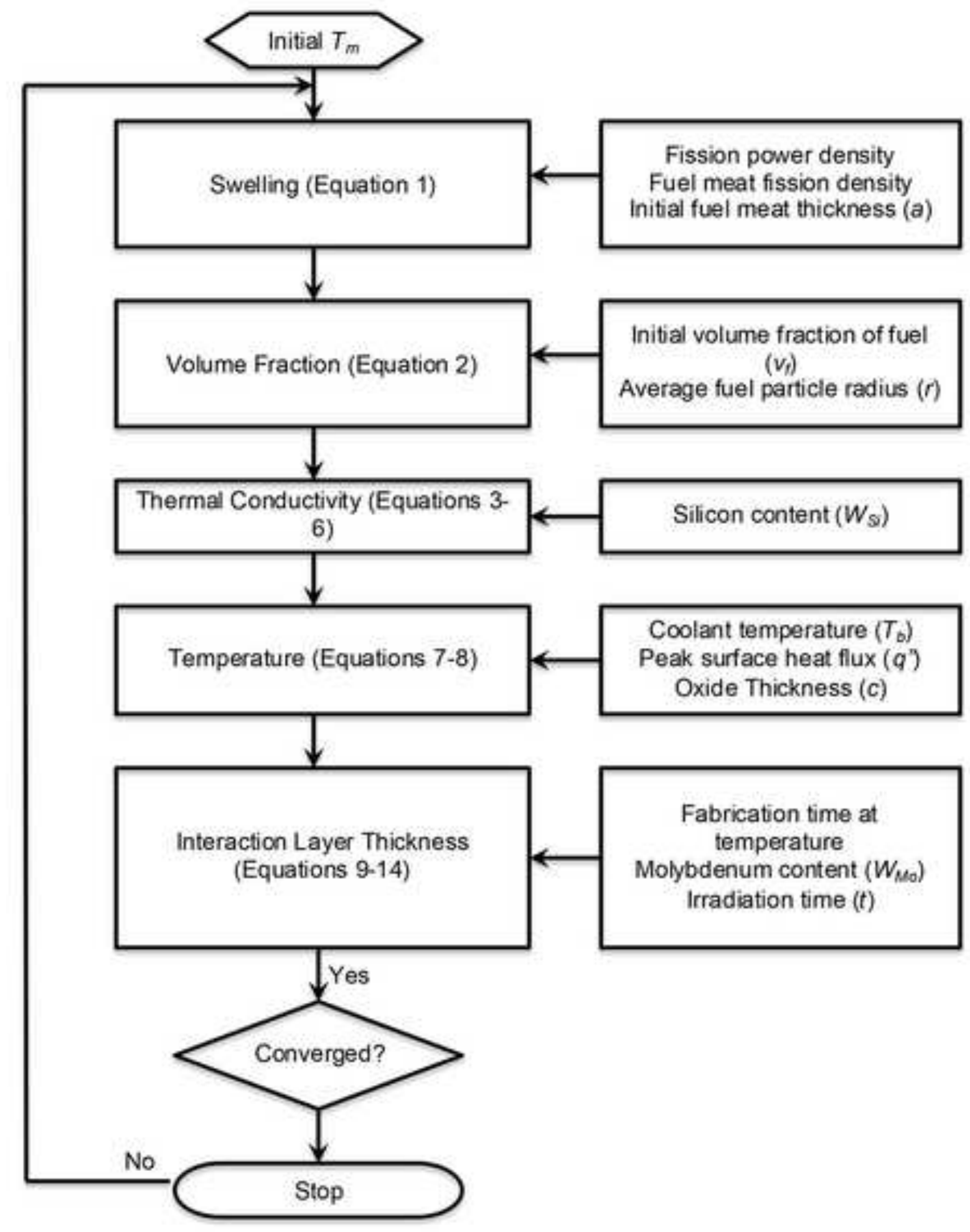

Figure 3

Fuel meat fission density Initial fuel meat thickness (a)

Initial volume fraction of fuel $\left(v_{t}\right)$

Average fuel particle radius $(r)$

Coolant temperature $\left(T_{b}\right)$

Fabrication time at temperature Irradiation time $(t)$
Molybdenum content ( $\left.W_{M_{0}}\right)$
Oxide Thickness (c)

Silicon content $\left(W_{S}\right)$

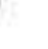

\section{.}

Thermal Conductivity (Equations 3-

Interaction Layer Thickness

(Equations 9-14) 


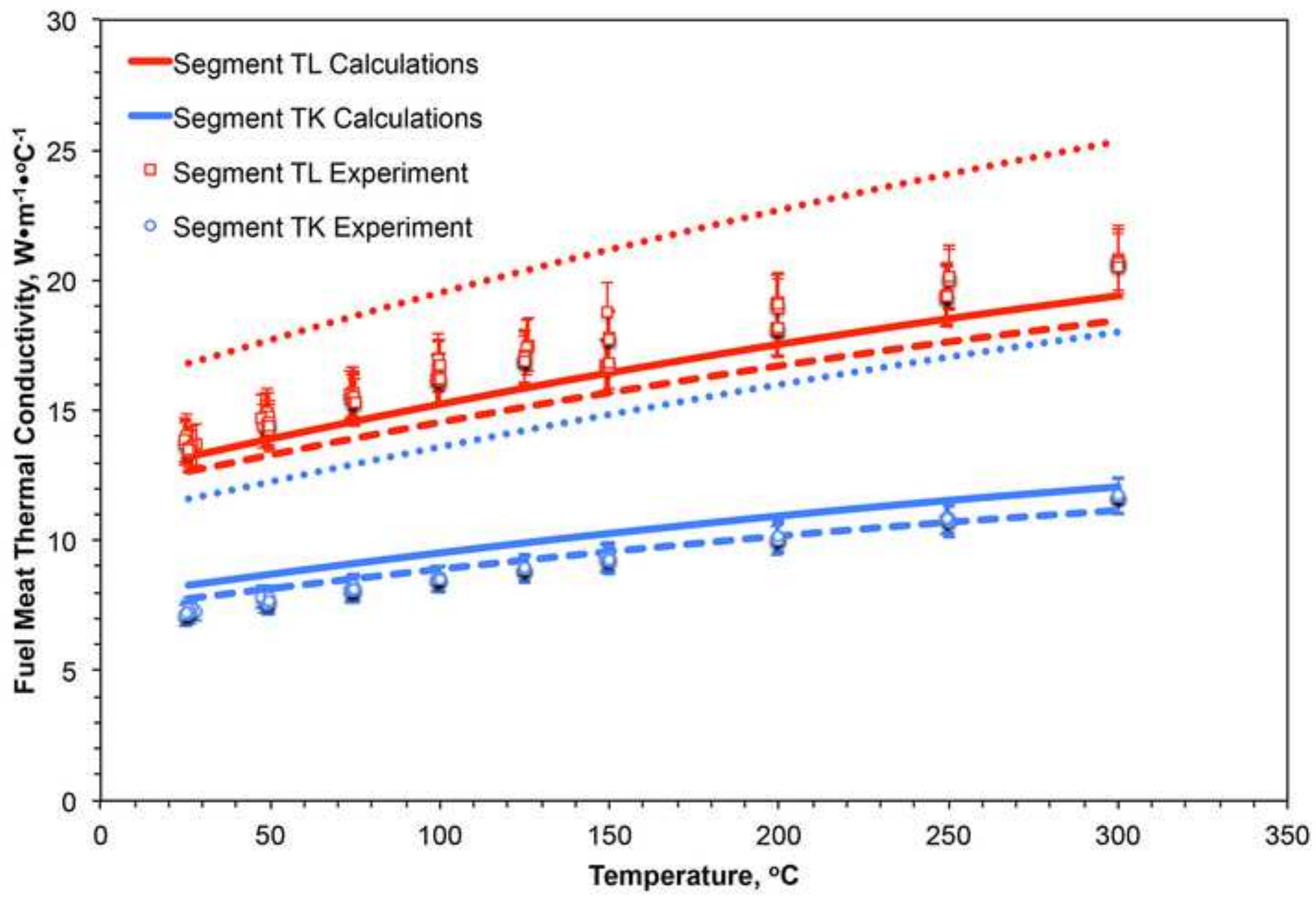




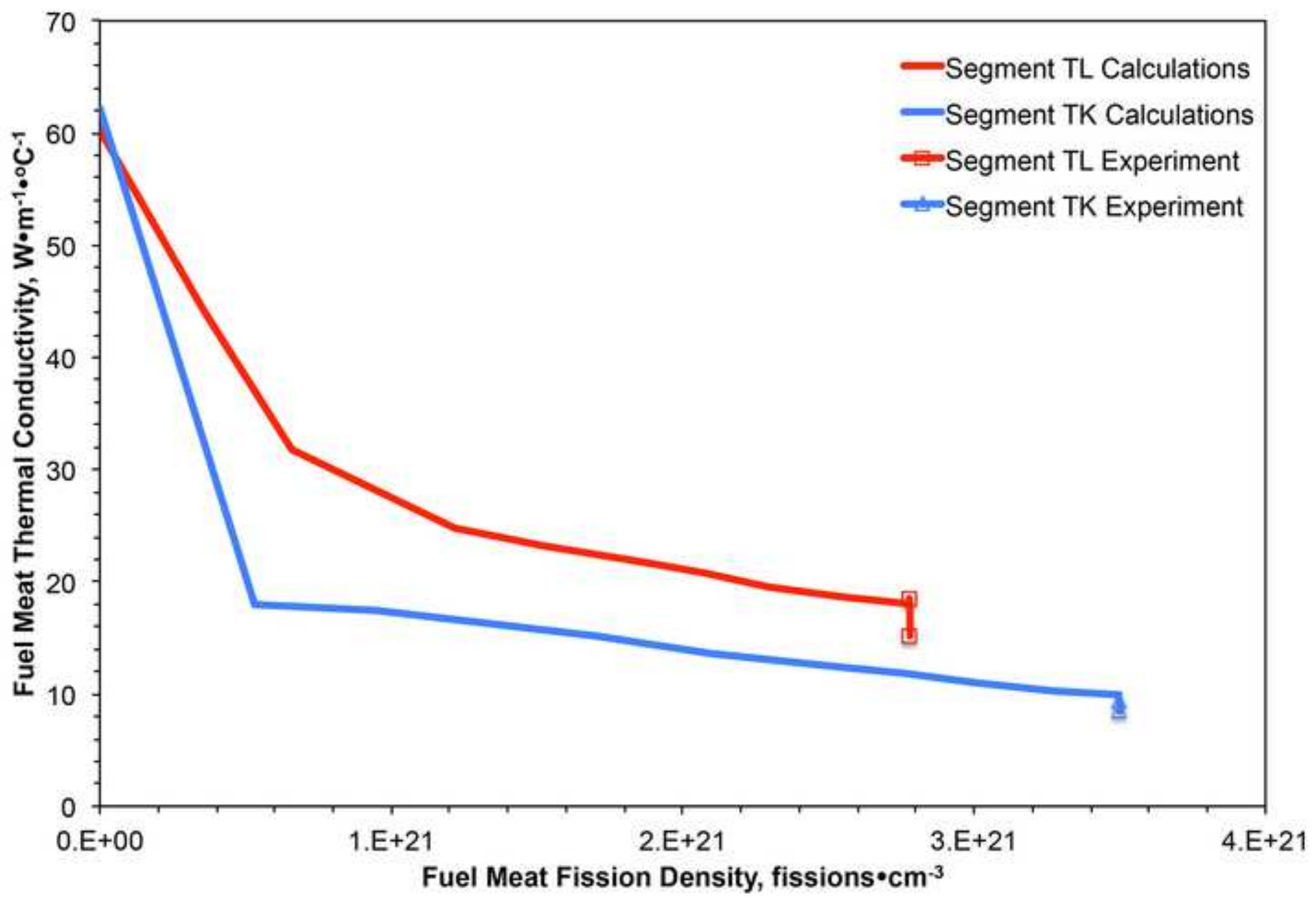




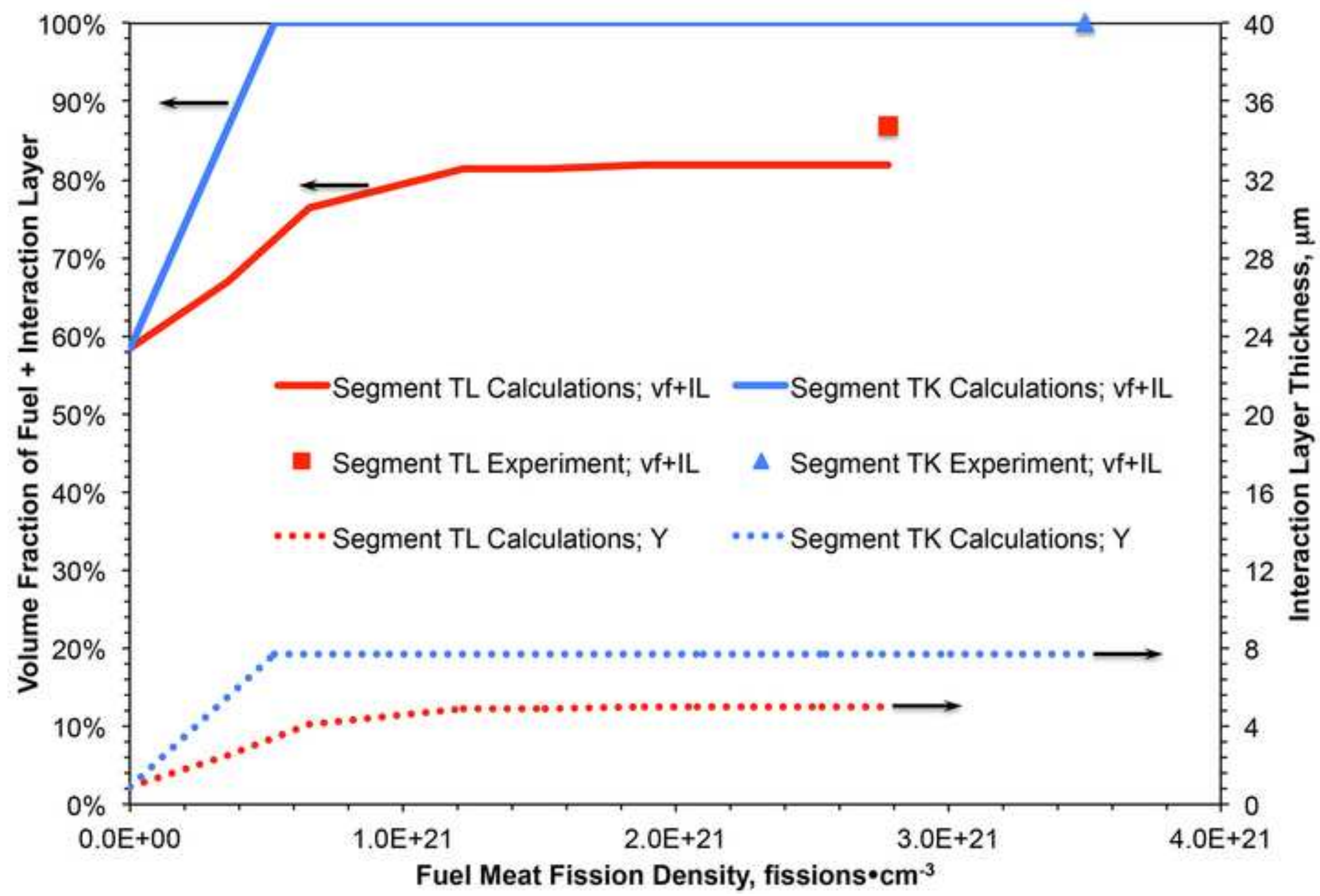




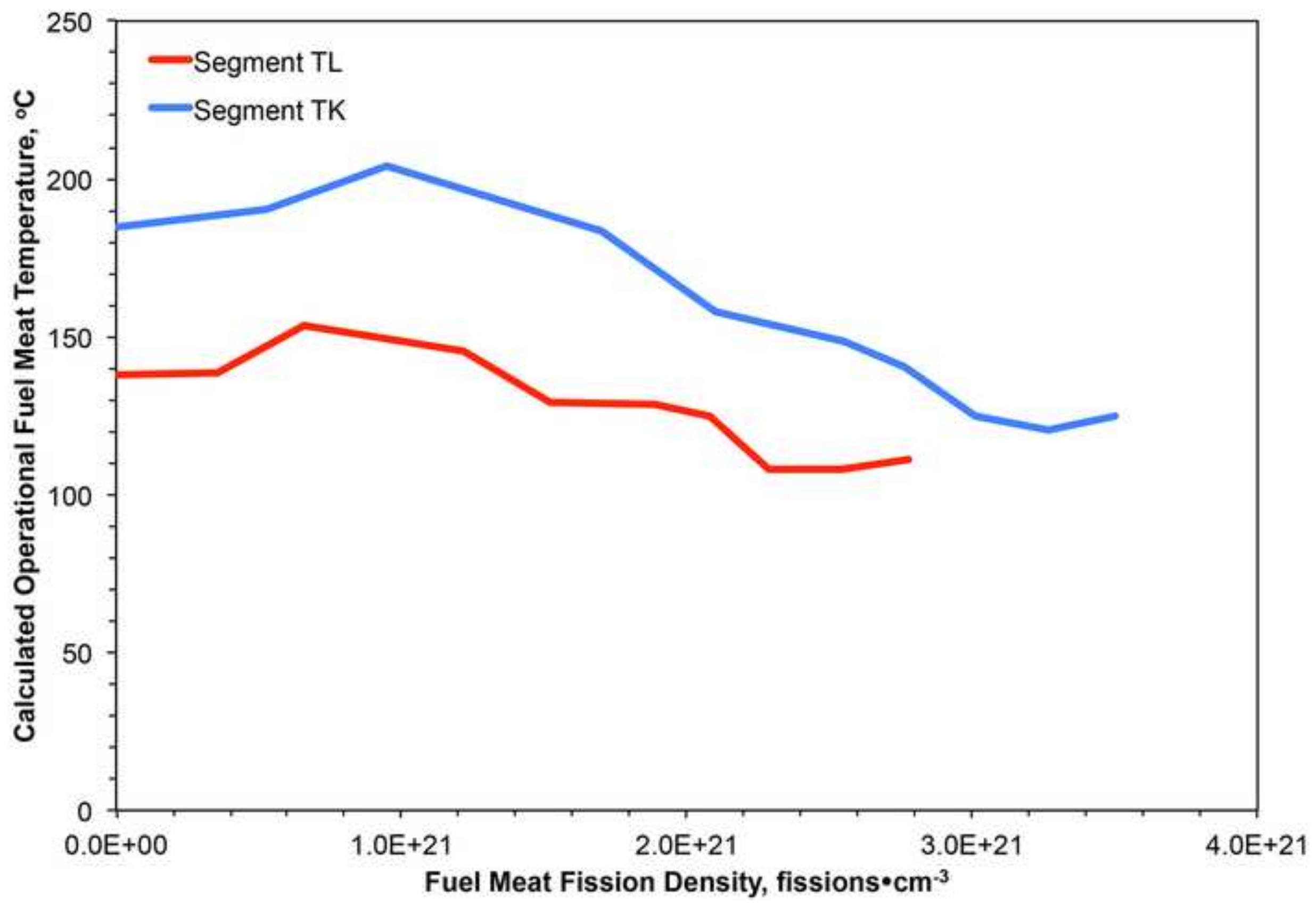




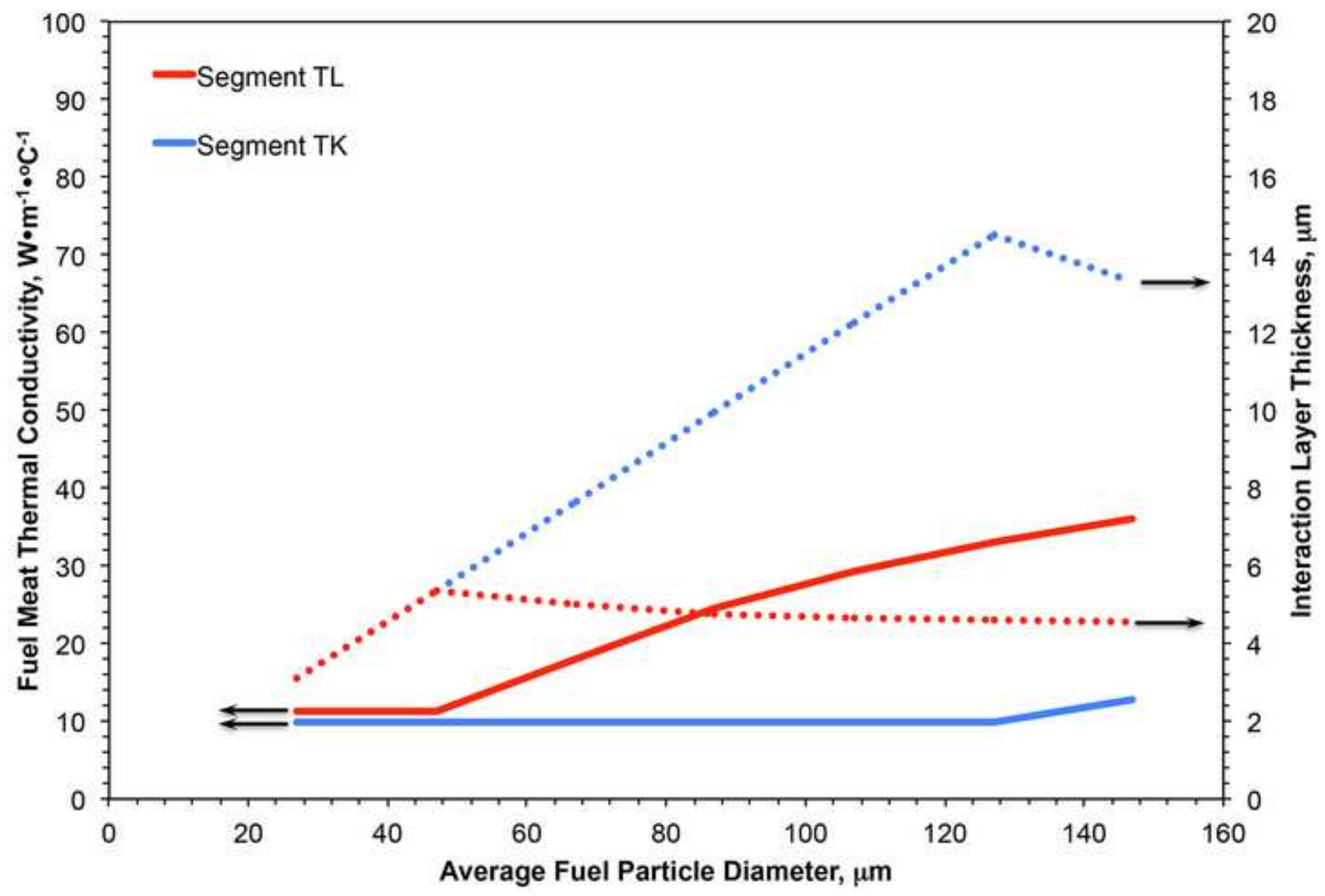




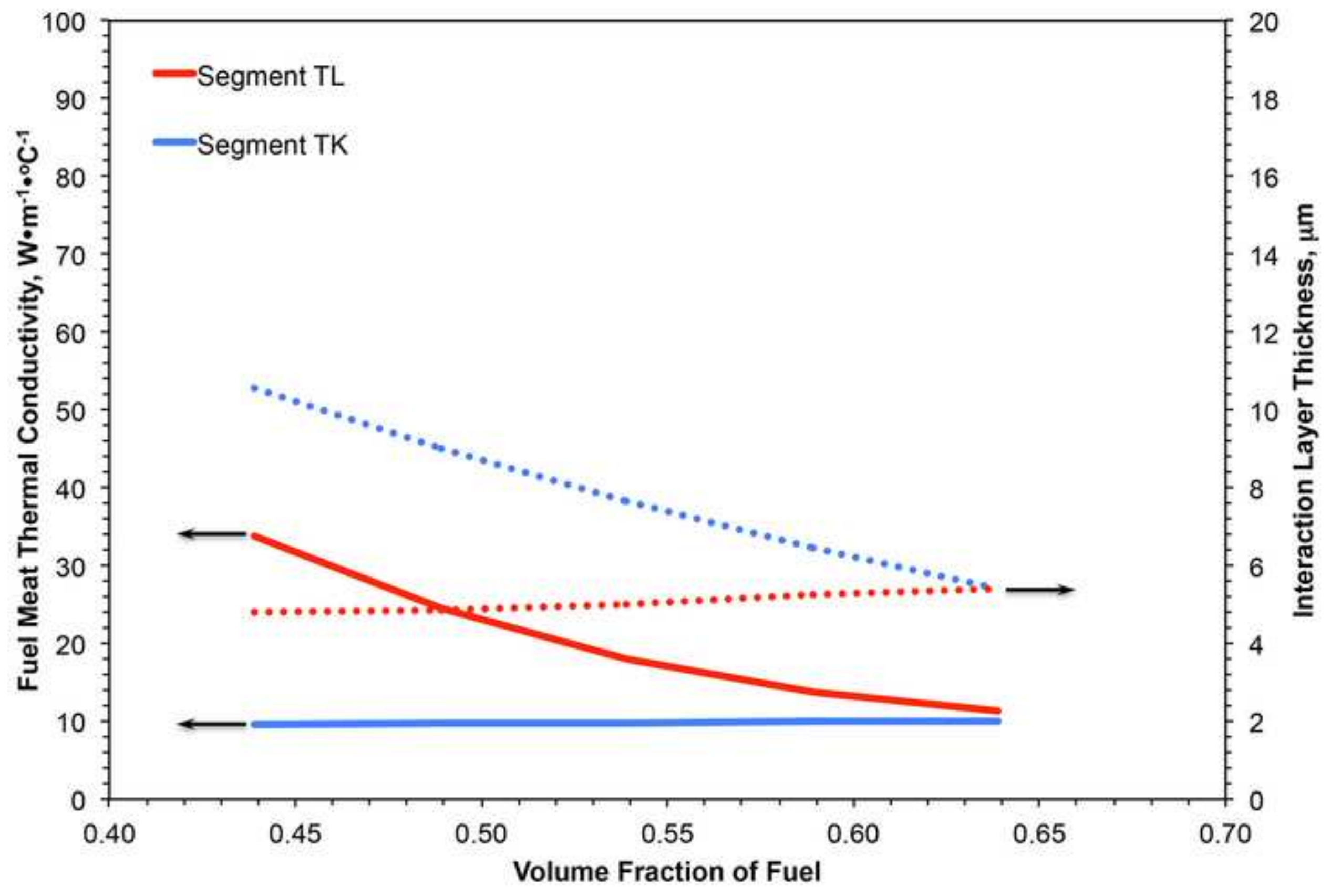



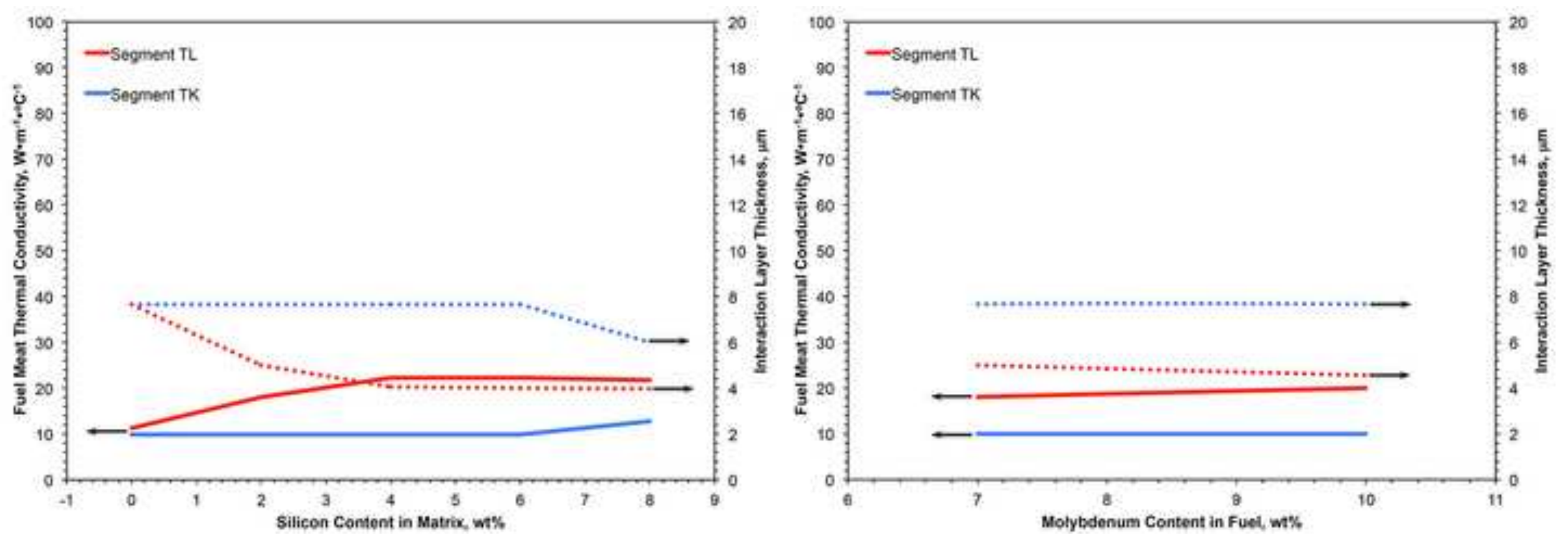

Figure 10 